\title{
Correction to: ACTH Producing Adenomas: Cushing's Disease
}

Raven McGlotten

\section{Correction to:}

\section{S. Llahana et al. (eds.), Advanced Practice in Endocrinology Nursing,} https://doi.org/10.1007/978-3-319-99817-6

The original version of Chapter 21 was inadvertently published without the author names "Daphne T. Adelman" and "Margaret F. Keil". These author names were included in the Acknowledgments text on Page 412 which has been removed and the author names have been included in the chapter.

Daphne T. Adelman

Northwestern University

Chicago, IL, USA

e-mail: d-adelman@northwestern.edu

Margaret F. Keil

Eunice Kennedy Shriver National Institute of Child Health and Human Development,

National Institutes of Health

Bethesda, MD, USA

e-mail: keilm@nih.gov

The updated online version of this chapter can be found at https://doi.org/10.1007/978-3-319-99817-6_21 